\title{
MARKETING NA CIÊNCIA DA INFORMAÇÃO
}

\author{
MARKETING EM LA CIENCIA DE LA INFORMACÍON
}

AMARAL, Sueli Angélica. Marketing na Ciência da Informação. Brasília: UnB, 2007. 230p. ISBN: 978-85230-0952-6

A obra é uma coletânea composta e organizada pela professora Sueli Angélica de Amaral, docente do Departamento de Ciência da Informação e Documentação da Universidade de Brasília. Este livro preenche uma extensa lacuna existente na literatura brasileira sobre o marketing da informação. Para contribuir na consolidação deste tema, a obra "vem aliar os fundamentos teóricos e metodológicos, às pesquisas desenvolvidas e às atividades práticas sobre marketing da informação" (p.13).

O livro é dividido em duas partes, sendo a primeira denominada de "Fundamentos teóricos e metodológicos" contendo

oito capítulos; e a segunda "Da pesquisa à pratica", com seis capítulos, tendo a participação de autores nacionais e internacionais que estão envolvidos com o marketing da informação, quer no ambiente acadêmico ou nas atividades práticas em unidades de informação.

O primeiro capítulo intitulado "Marketing e inteligência competitiva: aspectos complementares da gestão da informação e do conhecimento" é de responsabilidade da organizadora do livro, professora Sueli Angélica do Amaral; Neste capítulo são destacadas as relações intrínsecas da ótica de marketing e da inteligência competi- 
tiva na gestão da informação e do conhecimento. A autora ressalta que "[...] gestão da informação e do conhecimento, marketing e inteligência competitiva são aspectos complementares que devem ser considerados" (p.29-30). Conclui o capítulo chamando atenção para a capacitação dos profissionais da área, com o questionamento: "será que os profissionais da informação [...] estão preparados para assumir esses papéis e marcar presença na sociedade da informação ou na sociedade do conhecimento em que estamos inseridos, ou esses profissionais deixarão vazio esse espaço no seu mercado de trabalho?" (p.30).

No capítulo dois, intitulado "Serviços aos clientes: um imperativo de marketing", de autoria de Darlene E. Weingand - professora emérita da Universidade de Wisconsin, Madison, Estados Unidos (traduzido pelo bibliotecário Odilon Pereira da Silva) -, destaca-se a visão da biblioteca como uma organização de serviços na perspectiva do marketing e enfatiza o serviço de informação como um componente do marketing-mix. A autora argumenta que, com a mudança que permeia o campo da informação, as bibliotecas devem redefinir suas missões, seus objetivos e metas, assim como processos de planejamento e de marketing, sob pena de, se não o fizerem, continuarem oferecendo serviços com os paradigmas do passado.
Sob o título de "Gestão de Bibliotecas Universitárias com a implementação do Customer Relationship Management (CRM)", de responsabilidade dos autores Andrew Beheregarai Finger (Coordenador do curso de Administração de Negócios Internacionais do Centro Universitário Metodista IPA em Porto Alegre), Gardênia de Castro (Bibliotecária e supervisora do Laboratório de Orientação Cientifica do Centro Universitário Metodista IPA em Porto Alegre) e Marília Damiani Costa (docente do Departamento de Ciência da Informação da Universidade Federal de Santa Catarina), encontra-se o terceiro capítulo. Nele é apresentada a implementação do CRM em bibliotecas universitárias com foco no cliente, evidenciando que sua utilização possibilita descobrir clientes, conhecê-los melhor, manter comunicação, assegurar o recebimento de informações provenientes da biblioteca, além de garantir a manutenção desses clientes. Também é possível com essa técnica melhorar a gestão, principalmente no que diz respeito à tomada de decisão - por meio de informações providas de forma rápida e precisa -, proporcionar flexibilidade e agilidade nos processos de produção e ainda melhorar o planejamento e a qualidade das decisões.

O capitulo quatro, denominado de "Marketing e gestão da qualidade em serviços de informação: o relacionamento com os clientes como espaço de convergência de conceitos e praticas", tem como autor 
Waldomiro Vergueiro (professor titular da

Escola de Comunicações e Artes da Universidade de São Paulo). Nesse capítulo, o autor enfatiza a importância do relacionamento das unidades de informação com os clientes, delineando um espaço de convergência de conceitos e práticas.

O capitulo quinto, de autoria de Sofia Galvão Baptista (professora do Departamento de Ciência da Informação e Documentação da Universidade de Brasília), tem como título "Técnicas de marketing para gestores de unidades de informação". Apresenta uma teoria, possível de ser aplicada pelos gestores de unidades de informação, para planejar e formular ações estratégicas voltadas para a mudança de imagem não só do profissional que atua na biblioteca, mas também da própria biblioteca. A autora afirma que "é importante que o usuário tenha a melhor imagem dos serviços prestados pela unidade de informação. Para conquistar sua confiança, é preciso que a unidade ofereça produtos e serviços baseados em suas necessidades, prestando-lhes um bom atendimento e que isso seja percebido por ele" (p.93).

No sexto capítulo, intitulado "Estratégias de marketing na Internet para websites" de Ricardo Matos Chaim (analista de tecnologia da informação na Dataprev e professor no MBA em Administração Estratégica de Sistemas de Informação e no MBA em Fundos de Pensão da Fundação
Getulio Vargas), é enfatizada a importância dos websites para a oferta de produtos e serviços, tendo a Internet como canal de marketing.

O capítulo sétimo denominado de "Marketing e websites: recomendações para produzir e disponibilizar informações", de autoria de Rodrigo Octavio Beton Matta (graduado em administração e Analista do Banco Central do Brasil), discute os três aspectos do conteúdo informacional de um website (aspecto geográfico, aspecto textual e aspecto tecnológico). O autor alerta que na elaboração de websites deve merecer atenção, não apenas a informação explícita, mas também as implícitas, isso para manter a qualidade e ambientação da informação.

De responsabilidade dos autores Ivette Kafure (analista de sistemas e professora do Departamento de Ciência da Informação e Documentação da Universidade de Brasília) e Murilo Bastos da Cunha (professor do Departamento de Ciência da Informação e Documentação da Universidade de Brasília) o capítulo oitavo - "A usabilidade na gestão de marketing da biblioteca digital" - encerra a primeira parte do livro. Nesse capítulo é abordada a usabilidade na gestão de marketing de bibliotecas digitais. Os autores informam que "a usabilidade está relacionada às áreas de ergonomia, disciplina que reúne os estudos para adaptar o trabalho às características do ser 
humano, e IHC (Interface HumanoComputador), que faz referência ao diálogo ou à relação de utilização entre uma pessoa e um equipamento eletroeletrônico e/ou digital" (p.133). Afirmam que a usabilidade pode dar grande suporte à gestão de bibliotecas digitais e potencializar seu IHC por meio de recomendações que facilitem essa interação, tendo como suporte o modelo mental dos usuários (necessidades e expectativas).

$\mathrm{Na}$ segunda parte da obra depara-se com o capítulo nove sob o título "Técnicas de marketing em websites de bibliotecas universitárias brasileiras" de responsabilidade de Tatiara Paranhos Guimarães (bibliotecária de referência do Centro de Informação e Pesquisa da Embaixada dos Estados Unidos do Brasil). O texto destaca a aplicação das técnicas de marketing em websites de bibliotecas universitárias brasileiras. Apresenta resultados de pesquisa, desenvolvida pela autora em 2003, a respeito da gestão de websites de bibliotecas universitárias como instrumento de comunicação e relacionamento com seus públicos, a título de exemplo de implementação efetiva de técnicas de marketing em unidades de informação.

O capitulo dez - "Pesquisa experimental de promoção do Portal rede Governo" do professor Wagner Junqueira de Araújo (analista de sistema da Serpro e professor da Pós-graduação em Tecnologia da Informação na Universidade Paulista na Universidade de Brasília) -, apresenta os resultados obtidos com a utilização de três ferramentas de promoção (busca, banner e correio eletrônico) para promover um serviço do Governo na Internet, utilizando recursos da própria Internet como ferramenta de marketing.

O décimo primeiro capitulo, intitulado "Contribuição do marketing interno na conquista do prêmio de qualidade pela Divisão de Biblioteca e Documentação da ESALQ/USP", é de autoria de Márcia Regina Migliorato Saad (bibliotecária e diretora da Divisão de Biblioteca e Documentação da Escola Superior de Agricultura da USP). Relata a experiência na utilização de atividades desenvolvidas com o uso da técnica do marketing interno no Sistema Dibd.

O capitulo doze, "Atendimento de excelência: serviço de orientação personalizada ao usuário de biblioteca", tem como autoras kátia M. de Andrade Ferraz (bibliotecária e chefe da Seção de Circulação e Empréstimo da ESALQ/USP); Eliana Maria Garcia bibliotecária - chefe da Seção de Referência da Divisão de Bibliotecas e Documentação da ESALQ/USP), Sandra H. M. G. Ribeiro dos Santos (bibliotecária, diretora técnica do Serviço de Acesso a Informação da Divisão de Bibliotecas e Documentação da ESALQ/USP); Silvia Maria Zinsly (bibliotecária da Divisão de Bibliotecas e Documentação da E- 
SALQ/USP) e Ligiana Clemente do Carmo

Damiano (bibliotecária responsável pela

Biblioteca de Economia, Administração e

Sociologia da Divisão de Bibliotecas e Documentação da ESALQ/USP). O capitulo apresenta estudos realizados na Divisão de Biblioteca e Documentação da ESALQ/USP, demonstrando o atendimento de excelência realizado a partir do serviço de orientação personalizada oferecido ao usuário, utilizando-se das técnicas de marketing e benchmarketing.

O capitulo treze destaca os resultados de uma pesquisa de opinião, desenvolvida na biblioteca setorial de Economia, Administração e Sociologia da Escola Superior de Agricultura Luiz de Queiroz da Universidade de São Paulo, que evidencia as formas de aprimoramento dos serviços prestados aos usuários, bem como confirma a validade da visão do marketing em pesquisas dessa natureza, que podem ser desenvolvidas também em outros tipos de bibliotecas. O título do capítulo é "Pesquisa de opinião de usuário de biblioteca setorial" e foi escrito pelas autoras: Márcia Regina Migliorato Saad (bibliotecária e diretora da Divisão de Biblioteca e Documentação da Escola Superior de Agricultura da USP); Ligiana Clemente do Carmo Damiano (bibliotecária responsável pela Biblioteca de Economia, Administração e Sociologia da Divisão de Bibliotecas e Documentação da ESALQ/USP); Maria Cristina Olaio Villela (bibliotecária, diretora técnica da Divisão de Bibliotecas da Escola Politécnica da USP).

No último capitulo intitulado "Gestão da comunicação da informação para clientes internos de organizações hospitalares", dos autores Sergio Emidio de Azevedo Campos (administrador no Centro de Planejamento Oscar Niemeyer); Laene Pedro Gama (psicóloga e chefe da Divisão de Recursos Humanos do Hospital Universitário da UnB); Mariana Lopes C. da Silva Venzi (psicóloga, que atua como analista de recursos humanos no Hospital Anchieta em Brasília); Emily Cristina A. Oliveira (administradora de empresas e especialista em Gestão de Pessoas); Jose Divino de Brito Silva (graduado em Administração e trabalha como técnico em assuntos educacionais na UnB) e Ana Zélia Menezes Bonfim (pedagoga e Analista de Sistemas com especializações em Sistemas e Métodos e Gestão de Pessoas), é demonstrado como gerir a comunicação da informação em organizações hospitalares, considerando a comunicação do público interno, o endomarketing e a cultura organizacional.

Convido-os a lerem o livro, que apresenta contribuições inéditas para a Ciência da Informação brasileira. 
Nadina Aparecida Moreno nadina@uel.br

Doutora em Ciência da Informação pela Escola de Ciência da Informação da Universidade Federal de Minas Gerais (UFMG). Professora do Departamento de Ciência da Informação da Universidade Estadual de Londrina

Title:

Marketing in Information Science

\section{Título:}

Marketing em la Ciencia de La Informacíon 